\title{
Does right thoracotomy increase the risk of mitral valve reoperation?
}

Lars G. Svensson, MD, PhD, ${ }^{a}$ A. Marc Gillinov, MD, ${ }^{a}$ Eugene H. Blackstone, MD, ${ }^{a, b}$ Penny L. Houghtaling, MS, Kyung-Hwan Kim, MD, ${ }^{a}$ Gösta B. Pettersson, MD, PhD, ${ }^{a}$ Nicholas G. Smedira, MD, ${ }^{a}$ Michael K. Banbury, MD, and Bruce W. Lytle, MD

Supplemental material is available online.
From the Department of Thoracic and Cardiovascular Surgery ${ }^{\mathrm{a}}$ and Department of Quantitative Health Sciences, ${ }^{\text {b }}$ Cleveland Clinic, Cleveland, Ohio.

Received for publication March 10, 2006; revisions received April 10, 2007; accepted for publication April 16, 2007.

Address for reprints: Lars G. Svensson, $\mathrm{MD}, \mathrm{PhD}$, Department of Thoracic and Cardiovascular Surgery, Cleveland Clinic, 9500 Euclid Avenue/Desk F24, Cleveland, OH 44195 (E-mail: svenssl@ccf.org).

J Thorac Cardiovasc Surg 2007;134:677-82

$0022-5223 / \$ 32.00$

Copyright (C) 2007 by The American Association for Thoracic Surgery

doi:10.1016/j.jtcvs.2007.04.052
Objective: The study objective was to determine whether a right thoracotomy approach increases the risk of mitral valve reoperation.

Methods: Between January of 1993 and January of 2004, 2469 patients with mitral valve disease underwent 2570 reoperations (1508 replacements, 1062 repairs). The approach was median sternotomy in 2444 patients, right thoracotomy in 80 patients, and other in 46 patients. Multivariable logistic regression was used to identify factors associated with median sternotomy versus right thoracotomy, mitral valve repair versus replacement, hospital death, and stroke. Factors favoring median sternotomy $(P<.03)$ included coronary artery bypass grafting (30\% vs $2 \%)$, aortic valve replacement (39\% vs $2 \%$ ), tricuspid valve repair (27\% vs $13 \%)$, fewer previous cardiac operations, more recent reoperation, and no prior left internal thoracic artery graft. These factors were used to construct a propensity score for risk-adjusting outcomes.

Results: Hospital mortality was $6.7 \%(163 / 2444)$ for the median sternotomy approach and $6.3 \%(5 / 80)$ for the thoracotomy approach $(P=.9)$. Risk factors $(P<$ $.04)$ included earlier surgery date, higher New York Heart Association class, emergency operation, multiple reoperations, and mitral valve replacement. Stroke occurred in 66 patients $(2.7 \%)$ who underwent a median sternotomy and in 6 patients $(7.5 \%)$ who underwent a thoracotomy $(P=.006)$. Mitral valve replacement (vs repair) was more common in those receiving a thoracotomy $(P<.04)$.

Conclusions: Compared with median sternotomy, right thoracotomy is associated with a higher occurrence of stroke and less frequent mitral valve repair. Specific strategies for conducting the operation should be used to reduce the risk of stroke when right thoracotomy is used for mitral valve reoperation. In most instances, repeat median sternotomy, with its better exposure and greater latitude for concomitant procedures, is preferred.

A variety of reoperative approaches have been used for mitral valve surgery after previous cardiac surgery, including repeat median sternotomy, right thoracotomy, minimally invasive approaches, and robotic methods. ${ }^{1-11}$ Many favor the use of a right thoracotomy, citing reduced risk of damage to patent bypass grafts and need for less dissection to expose the mitral valve. ${ }^{3,4,6,8}$ However, the right thoracotomy approach raises specific technical issues, including adequacy of mitral valve exposure and myocardial protection, and need for peripheral cannulation for cardiopulmonary bypass (CPB). Although median sternotomy has generally been our favored approach for mitral valve reoperation, some surgeons in our group have periodically used a right thoracotomy. The objective of this study was to determine whether a right thoracotomy increases the risk of mitral reoperation compared with a median sternotomy. 


\author{
Abbreviations and Acronyms \\ $\mathrm{CABG}=$ coronary artery bypass grafting \\ $\mathrm{CL}=$ confidence limit \\ $\mathrm{CPB}=$ cardiopulmonary bypass
}

\section{Materials and Methods \\ Patients}

From January 1993 to January 2004, 2570 reoperations were performed at the Cleveland Clinic in 2469 adults (aged $\geq 18$ years) with mitral valve disease. The initial procedure was any cardiac operation performed through a median sternotomy; 483 patients had previously undergone a mitral valve procedure. The reoperative approach to the mitral valve was through a repeat median sternotomy in 2444 patients (95\%), right thoracotomy in 80 patients (3.1\%), and other (minimally invasive approaches) in 46 patients $(1.9 \%)$. Because minimally invasive incisions were developed only recently, encompass a variety of different approaches, and are used infrequently, patients with this incision were excluded from the analyses. At reoperation, 1508 patients underwent mitral valve replacement, and 1062 patients underwent mitral valve repair. The mean age at reoperation was $64 \pm 12$ years, and 55\% were men (Table 1).

\section{Operative Approach}

Repeat median sternotomy was performed using an oscillating saw; in most instances, femoral vessels were exposed in case urgent institution of CPB became necessary. CPB was established using central cannulation, and cardiac arrest was achieved with aortic clamping and antegrade and retrograde cardioplegia. The mitral valve was accessed either through the left atrium or an extended transseptal incision.

Before the thoracotomy, the extent of descending aortic arteriosclerosis was assessed by transesophageal echocardiography; in the case of severe descending aortic arteriosclerosis, a median sternotomy approach was favored. The right thoracotomy approach included single-lung ventilation and entry into the chest through the fourth or fifth or intercostal space. Femoral cannulation was used for CPB. In 73 of 80 patients (91\%), the operation was performed with systemic hypothermia and ventricular fibrillation; in the other 7 patients, the aorta was clamped and cardioplegia was administered. The mitral valve was accessed through a left atriotomy. After the mitral valve procedure, the lungs were inflated and the heart was filled to facilitate deairing at completion of left atrial closure. In addition, a vent was placed across the mitral valve and, combined with an aortic root vent, used to complete deairing before weaning from CPB. Deairing was monitored by transesophageal echocardiography. Seven patients (8.8\%) who received a thoracotomy and 71 patients $(2.9 \%)$ who received a sternotomy had hypothermic circulatory arrest.

\section{End Points}

End points included stroke, hospital mortality, and mitral valve repair versus replacement. Stroke was defined according to The Society of Thoracic Surgeons database: permanent stroke - central neurologic deficit persisting more than 72 hours after operation.
Hospital mortality was defined as 30-day and in-hospital death. Mitral valve repair versus replacement applied to the type of mitral valve procedure performed in a subgroup of patients without previous mitral valve replacement.

\section{Data Analysis}

Operative approach and propensity matching. By multivariable logistic regression analysis, factors identified as favoring a repeat median sternotomy rather than a right thoracotomy at reoperation included the need for concomitant coronary artery bypass grafting (CABG) $(39 \%$ vs $1 \%)$, aortic valve replacement (30\% vs $0 \%$ ), tricuspid valve repair (27\% vs $15 \%$ ), fewer previous cardiac operations, more severe heart failure, more recent reoperative date, no prior left internal thoracic artery graft, and 3-system coronary artery disease (parsimonious model). Previous mitral valve repair or replacement, previous aortic valve replacement, chronic obstructive pulmonary disease, and emergency operation were not associated with the operative approach. Circulatory arrest data were included in the parsimonious logistic regression model.

To generate a propensity score for each patient, we first augmented the parsimonious logistic model with variables representing every category of potential risk factor listed in Appendix E1, 53 in total $(\mathrm{C}=.92) .{ }^{12,13}$ Then, with this augmented model, a propensity score for operative approach was generated for each patient for use in thorough risk adjustment.

Outcomes and operative approach. The association of operative approach with hospital mortality, perioperative stroke, and mitral valve repair versus replacement, adjusted for risk factors and propensity score, was quantified by multivariable logistic regression analysis. Selection of other risk factors used automated stepwise selection and bootstrap bagging, using 100 bootstrap samples. ${ }^{14}$ Variables significant at a $P$ value of .05 or less and appearing in at least $40 \%$ of the bootstrap analyses were identified as risk factors. A generalized estimating equation with logit link was used for final parameter estimates to compensate for fixed variables in patients who underwent multiple mitral valve reoperations. ${ }^{15}$

\section{Presentation}

Means are accompanied by their standard deviation; however, when distribution of values was skewed, the median and 15th and 85th percentiles are given. Percentages are accompanied by $68 \%$ confidence limits (CLs) (equivalent to \pm 1 standard error). Except for interpretable binary variables, logistic coefficients and their standard error are presented rather than odds ratios, in part because the use of linearizing transformations for continuous variables renders odds ratios difficult to interpret. Odds ratios are shown for dichotomous variables.

\section{Results}

\section{Hospital Mortality}

Operative approach was not associated with hospital mortality. There were 168 hospital deaths (6.6\%; CL 6.1\%-7.1\%): 163 (6.7\%; CL 6.1\%-7.1\%) in the median sternotomy group and 5 (6.3\%; CL 3.6\%-10.2\%) in the right thoracotomy group ( $P=$ .9). Risk factors included earlier date of operation, higher New York Heart Association functional class, emergency reopera- 
TABLE 1. Patient and operative characteristics by surgical approach

\begin{tabular}{|c|c|c|}
\hline \multirow[b]{3}{*}{ Variable } & \multicolumn{2}{|c|}{ Surgical approach } \\
\hline & Median sternotomy $(n=2444)$ & Thoracotomy ( $\mathrm{n}=\mathbf{8 0}$ ) \\
\hline & No. $(\%)$ & No. $(\%)$ \\
\hline \multicolumn{3}{|l|}{ Patient } \\
\hline Age $(y$, mean $\pm S D)$ & $64 \pm 12$ & $63 \pm 11$ \\
\hline Male & $1337(55)$ & $57(71)$ \\
\hline COPD & $634(26)$ & $14(18)$ \\
\hline Renal failure & $247(10)$ & $14(18)$ \\
\hline 3-system CAD* & $731 / 2133(34)$ & $32 / 61(52)$ \\
\hline Atrial fibrillation & $751(31)$ & $18(23)$ \\
\hline Cerebrovascular/carotid disease & $876(36)$ & $18(23)$ \\
\hline Aortic valve regurgitation & $\mathrm{n}=2079$ & $\mathrm{n}=35$ \\
\hline None & $1037(50)$ & $26(74)$ \\
\hline $1+$ & $414(20)$ & $6(17)$ \\
\hline $2+$ & $274(13)$ & $3(9)$ \\
\hline $3+$ & $174(8)$ & 0 \\
\hline $4+$ & $180(9)$ & 0 \\
\hline Mitral valve regurgitation & $\mathrm{n}=2405$ & $\mathrm{n}=78$ \\
\hline None & $229(9)$ & $13(17)$ \\
\hline $1+$ & $139(6)$ & $3(4)$ \\
\hline $2+$ & $240(10)$ & $3(4)$ \\
\hline $3+$ & $640(27)$ & $15(19)$ \\
\hline $4+$ & $1157(48)$ & $44(56)$ \\
\hline Mitral valve stenosis & $\mathrm{n}=2444$ & $\mathrm{n}=80$ \\
\hline Yes & $471(19)$ & $8(10)$ \\
\hline No & $1973(81)$ & $72(90)$ \\
\hline \multicolumn{3}{|l|}{ NYHA class } \\
\hline I & $227(9)$ & $6(8)$ \\
\hline II & $1093(45)$ & $35(44)$ \\
\hline III & $816(33)$ & $26(32)$ \\
\hline IV & $308(13)$ & $13(16)$ \\
\hline Endocarditis & $326(13)$ & $9(11)$ \\
\hline Emergency reoperation & $56(2.3)$ & $2(2.5)$ \\
\hline Diabetes & $444 / 2379(19)$ & $10 / 76(13)$ \\
\hline \multirow[t]{2}{*}{ Preoperative bilirubin $\left(\mathrm{mg} / \mathrm{dL}^{-1}\right) \dagger$} & $\mathrm{n}=2019$ & $\mathrm{n}=71$ \\
\hline & $0.8(0.5-1.6)$ & $1.0(0.6-2.7)$ \\
\hline Aortic valve replacement & $456(19)$ & $13(16)$ \\
\hline Mitral valve replacement & 460 (19) & $19(24)$ \\
\hline Mitral valve repair & $674(27)$ & $13(16)$ \\
\hline CABG & $1110(45)$ & $53(66)$ \\
\hline LITA graft & $555(23)$ & $37(46)$ \\
\hline$>2$ previous operations & $619(25)$ & $40(50)$ \\
\hline \multicolumn{3}{|l|}{ Current operation } \\
\hline \multirow[t]{2}{*}{ Aortic clamp time (min) } & $\mathrm{n}=2423$ & $\mathrm{n}=7$ \\
\hline & $94 \pm 41$ & $57 \pm 37$ \\
\hline \multirow[t]{2}{*}{ CPB time (min) } & $\mathrm{n}=2439$ & $\mathrm{n}=78$ \\
\hline & $132 \pm 58$ & $123 \pm 43$ \\
\hline Aortic valve replacement & $724(30)$ & $0(0)$ \\
\hline CABG & $955(39)$ & $1(1)$ \\
\hline Tricuspid valve repair & $671(27)$ & $12(15)$ \\
\hline Tricuspid valve replace & $46(2)$ & $0(0)$ \\
\hline \multirow[t]{2}{*}{$\mathrm{RBC}$ transfusion $(\%)$} & $\mathrm{n}=2310$ & $\mathrm{n}=71$ \\
\hline & $1658(72 \%)$ & $58(82 \%)$ \\
\hline
\end{tabular}

$S D$, Standard deviation; $C O P D$, chronic obstructive pulmonary disease; $C A D$, coronary artery disease; NYHA, New York Heart Association; $C A B G$, coronary artery bypass grafting; $C P B$, cardiopulmonary bypass; $L I T A$, left internal thoracic artery; $R B C$, red blood cell. *Denominator is patients undergoing coronary angiography. +15 th, 50th (median), and 85 th percentiles. 
TABLE 2. Incremental risk factors for hospital mortality

\begin{tabular}{|c|c|c|c|c|}
\hline Factor & Estimate \pm SE & $P$ & Reliability (\%)* & Odds ratiot \\
\hline \multicolumn{5}{|l|}{ Operative approach } \\
\hline Right thoracotomy & $-0.73 \pm 0.48$ & .13 & - & 0.48 \\
\hline Propensity score & $1.11 \pm 0.93$ & .23 & - & \\
\hline \multicolumn{5}{|l|}{ Acuity } \\
\hline Higher preoperative & $0.29 \pm 0.109$ & .008 & 63 & \\
\hline \multicolumn{5}{|l|}{ NYHA class } \\
\hline Emergency reoperation & $2.4 \pm 0.34$ & $<.0001$ & 99 & 10.8 \\
\hline \multicolumn{5}{|l|}{ Previous cardiac operation } \\
\hline CABG & $0.74 \pm 0.21$ & .0004 & 76 & 2.1 \\
\hline Other & $1.08 \pm 0.27$ & $<.0001$ & 76 & 2.9 \\
\hline \multicolumn{5}{|l|}{ Cardiac comorbidity } \\
\hline Less severe mitral regurgitation $\ddagger$ & $-0.74 \pm 0.19$ & $<.0001$ & 89 & \\
\hline \multicolumn{5}{|l|}{ Noncardiac comorbidity } \\
\hline BUN§ & $0.79 \pm 0.175$ & $<.0001$ & 89 & \\
\hline Bilirubin§ & $0.41 \pm 0.147$ & .006 & 83 & \\
\hline Carotid disease & $0.65 \pm 0.20$ & .0009 & 59 & \\
\hline \multicolumn{5}{|l|}{ Reoperation } \\
\hline Higher surgery number & $0.28 \pm 0.118$ & .02 & 59 & \\
\hline Earlier date of operation & $-0.142 \pm 0.034$ & $<.0001$ & 94 & \\
\hline Mitral valve replacement & $0.45 \pm 0.20$ & .02 & 56 & 1.6 \\
\hline Tricuspid valve repair & $0.64 \pm 0.195$ & .001 & 70 & 1.9 \\
\hline Tricuspid valve replacement & $1.27 \pm 0.51$ & .01 & 63 & 3.6 \\
\hline Aortic valve replacement & $0.46 \pm 0.191$ & .01 & 59 & 1.6 \\
\hline
\end{tabular}

$S E$, Standard error; NYHA, New York Heart Association; $C A B G$, coronary artery bypass grafting; BUN, blood urea nitrogen; *Percent of time factor appeared in 500 bootstrap analyses. For dichotomous variables. $¥$ Grade $4+$. §Natural logarithmic transformation.

tion, carotid disease, previous $\mathrm{CABG}$ or other complex operation, tricuspid repair or replacement, multiple reoperations, need for concurrent CABG, aortic valve replacement, and mitral valve replacement versus repair (Table 2).

\section{Stroke}

Stroke was associated with right thoracotomy and occurred in 67 patients $(2.7 \%$; CL $2.4 \%-3.1 \%)$ who received a median sternotomy and 6 patients (7.5\%; CL 4.6\%-11.7\%) who received a right thoracotomy $(P=.006)$. Imaging studies suggested that 5 of the 6 thoracotomy-associated strokes appeared to be embolic in origin (Table 3). Other risk factors for stroke included advanced age and higher bilirubin (Table 4). Risk of stroke in older patients was further increased if circulatory arrest was used; however, longer duration of circulatory arrest was not a predictor. Circulatory arrest times were $19 \pm 19$ minutes for thoracotomy and $20 \pm 20$ minutes for sternotomy.

\section{Mitral Valve Replacement}

Mitral valve replacement was performed in 1508 reoperations $(61 \%)$. After adjustment for other factors, right thoracotomy emerged as a risk factor for mitral valve replacement $(P=.004$; Table E1). Other risk factors included previous mitral valve surgery $(P<.0001)$, mitral stenosis $(P<.0001)$, and earlier date of operation $(P=.01)$.

TABLE 3. Stroke after thoracotomy

\begin{tabular}{llll}
\hline Age $(\mathbf{y})$ & \multicolumn{1}{c}{ Clinical } & \multicolumn{1}{c}{ CT/MRI } & Outcome \\
\hline 70 & Left hemiplegia & Frontal gyrus 3- to 4-mm attenuation & Recovered \\
56 & Right hemiplegia, seizures & Left MCA and cerebellar infarcts & Partial recovery \\
56 & Left hemiplegia, thrombolytics, coma & ACA and MCA territory infarcts, later & Autopsy: multiple infarcts and frontal \\
& & frontal hemorrhage & and pontine hemorrhages \\
52 & Seizures, left hemiplegia, nystagmus & $\begin{array}{l}\text { Right cerebellar attenuation } \\
\text { Embolic right frontal and occipital infarcts }\end{array}$ & Do not resuscitate; died \\
66 & Seizures, coma & Left frontal, cerebellar, and right basal & Partial recovery
\end{tabular}

$C T / M R I$, Computed tomography/magnetic resonance imaging; $M C A$, middle cerebral artery; ACA, anterior cerebral artery. 
TABLE 4. Incremental risk factors for stroke after mitral valve reoperation

\begin{tabular}{|c|c|c|c|}
\hline Factor & Estimate $\pm \mathrm{SE}$ & $\boldsymbol{P}$ & Reliability $(\%)^{*}$ \\
\hline \multicolumn{4}{|l|}{ Operative approach } \\
\hline Right thoracotomy & $1.38 \pm 0.58 \dagger$ & .02 & - \\
\hline Propensity score & $-3.2 \pm 2.1$ & .13 & - \\
\hline \multicolumn{4}{|l|}{ Demography } \\
\hline Older & $0.34 \pm 0.153$ & .02 & 57 \\
\hline Circulatory arrest and older age interaction & $0.022 \pm 0.0056$ & .0001 & 52 \\
\hline \multicolumn{4}{|l|}{ Noncardiac comorbidity } \\
\hline Higher preoperative bilirubin§ & $0.55 \pm 0.21$ & .008 & 51 \\
\hline
\end{tabular}

$S E$, Standard error. *Percent of time factor appeared in 500 bootstrap analyses. +0 dds ratio for stroke 3.9 (68\% confidence interval 2.2-7.1). $\ddagger$ Exp(age/50), exponential transformation. §Natural logarithmic transformation.

\section{Discussion}

\section{Principal Findings}

Hospital mortality for mitral valve reoperation was similar with a right thoracotomy or repeat median sternotomy. However, right thoracotomy was associated with higher risk of stroke and reduced likelihood of mitral valve repair.

\section{Right Thoracotomy for Mitral Valve Reoperation}

Because right thoracotomy provides access to the mitral valve without the need for extensive mediastinal dissection, many surgeons consider it a useful approach. ${ }^{1-6,8}$ It is attractive when repeat median sternotomy is particularly hazardous (eg, patent bypass graft apposed to the sternum, previous sternal debridement). Reoperation through a right thoracotomy generally entails peripheral cannulation (usually femoral) and ventricular fibrillation during the mitral procedure. It is important that the heart be kept fibrillating while it is open to air to prevent accidental ejection of air. Femoral arterial cannulation can cause embolic stroke if there is aortic arteriosclerosis, and this may have contributed to the increased risk of stroke in the right thoracotomy group. In addition, although standard deairing techniques are described, incomplete deairing of the heart may contribute to neurologic dysfunction with this approach.

There are several other considerations when performing mitral reoperation through a right thoracotomy. Femoral cannulation has been associated with local complications and retrograde aortic dissection. Right thoracotomy frequently affords somewhat limited exposure of the mitral valve, increasing difficulty of the mitral operation, and potential reduction of the probability of valve repair. Any aortic regurgitation further impairs visualization of the valve. Finally, it is not possible to bypass left-sided coronary arteries or address aortic valve pathology with this approach.

\section{Repeat Median Sternotomy}

For the reasons listed above, repeat median sternotomy has been our favored approach for mitral valve reoperation. In this series, it was specifically preferentially used in patients who required $\mathrm{CABG}$ or aortic valve surgery and in those with aortic regurgitation. Although patients undergoing the 2 approaches differed, there were a sufficient number of patients and events to enable use of multivariable analysis with propensity adjustment to explore the impact of operative approach on outcome. In our hands, repeat median sternotomy was generally superior. Indeed, this has influenced our practice, and fewer patients are undergoing thoracotomy for reoperation (Figure 1).

\section{Limitations}

This is a large, diverse group of patients in whom the choice of operative approach was at the surgeons' discretion. The number of patients undergoing a right thoracotomy was too small to use propensity matching to obtain a fair comparison between groups; instead, we used propensity adjustment of multivariable models. However, no propensity-based strategy can compensate or account for unrecorded factors, such as degree of ascending arteriosclerosis, considered by surgeons in choosing their approach or for differences between groups. A randomized study would provide the best comparison, but given the complexity of these cases, this is unlikely to be done. We did not evaluate minimally invasive reoperative approaches, such

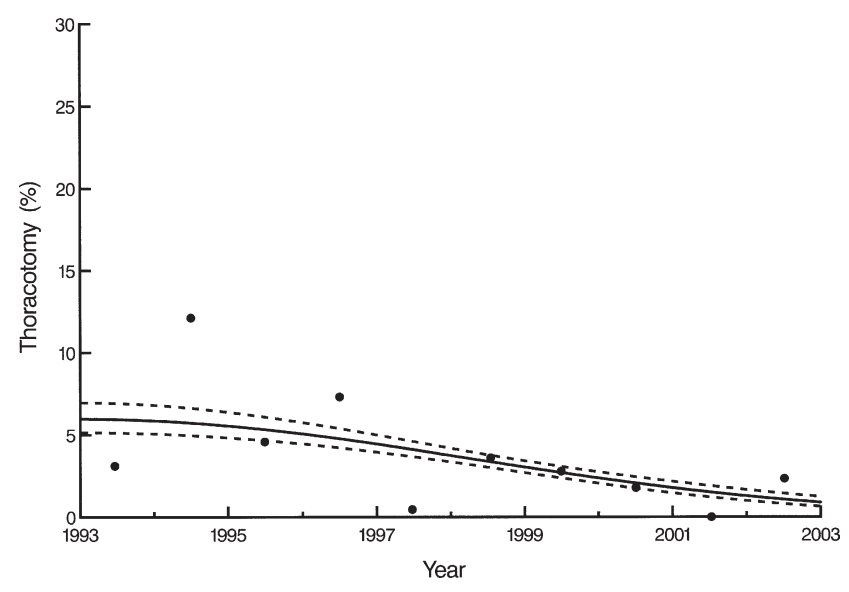

Figure 1. Trend in thoracotomy use over time. 
as endoscopic or robotic reoperations; these may prove useful and safe for isolated mitral valve procedures. ${ }^{2,3,7}$

\section{Clinical Implications}

In most instances, we recommend using a median sternotomy approach for mitral valve reoperation because it is associated with reduced risk of stroke and offers better exposure and greater latitude to perform concomitant cardiac procedures. Is there still a place for right thoracotomy reoperations for mitral valve disease? This study suggests that there are few instances for which such a strategy should be used. For patients with internal thoracic artery grafts jeopardized by repeat median sternotomy, multiple previous sternotomies, or previous muscle flaps for mediastinitis, a right thoracotomy may be easier or safer. When a right thoracotomy is used, cannulation strategy should be optimized to reduce the risk of embolic stroke. Preoperative (computed tomography scan) or intraoperative (transesophageal echocardiogram) screening of the descending aorta for arteriosclerosis is recommended. If there is any aortic arteriosclerosis or femoral arterial disease, axillary artery cannulation is preferred to femoral cannulation; such a strategy might have reduced the occurrence of stroke in this series. Because valve exposure may be challenging through a right thoracotomy, sternotomy is preferable if a complex mitral valve repair is anticipated.

\section{References}

1. Thompson MJ, Behranwala A, Campanella C, Walker WS, Cameron EW. Immediate and long-term results of mitral prosthetic replacement using a right thoracotomy beating heart technique. Eur J Cardiothorac Surg. 2003;24:47-51; discussion.

2. Onnasch JF, Schneider F, Falk V, Mierzwa M, Bucerius J, Mohr FW. Five years of less invasive mitral valve surgery: from experimental to routine approach. Heart Surg Forum. 2002;5:132-5.

3. Onnasch JF, Schneider F, Falk V, Walther T, Gummert J, Mohr FW. Minimally invasive approach for redo mitral valve surgery: a true benefit for the patient. J Card Surg. 2002;17:14-9.

4. Byrne JG, Karavas AN, Adams DH, Aklog L, Aranki SF, Filsoufi F, et al. The preferred approach for mitral valve surgery after CABG right thoracotomy, hypothermia and avoidance of LIMA-LAD graft. J Heart Valve Dis. 2001;10:584-90.

5. Holman WL, Goldberg SP, Early LJ, McGiffin DC, Kirklin JK, Cho $\mathrm{DH}$, et al. Right thoracotomy for mitral reoperation: analysis of technique and outcome. Ann Thorac Surg. 2000;70:1970-3.

6. Pretre R, Ye Q, Zund G, Turina MI. Approach to the mitral valve through a right thoracotomy in potentially hazardous reoperation. J Card Surg. 1999;14:112-5.

7. Vleissis AA, Bolling SF. Mini-reoperative mitral valve surgery. J Card Surg. 1998;13:468-70.

8. Steimle CN, Bolling SF. Outcome of reoperative valve surgery via right thoracotomy. Circulation. 1996;94:III26-8.

9. Svensson LG. Minimal-access "J" or "j" sternotomy for valvular, aortic, and coronary operations or reoperations. Ann Thorac Surg. 1997;64:1501-3.

10. Svensson LG, D'Agostino RS. "J" incision minimal-access valve operations. Ann Thorac Surg. 1998;66:1110-2.

11. Svensson LG, D'Agostino RS. Minimal-access aortic and valvular operations, including the "J/j" incision. Ann Thorac Surg. 1998;66: 431-5.

12. Rosenbaum PR, Rubin DB. The central role of the propensity score in observational studies for causal effects. Biometrika. 1983;70:4155 .

13. Blackstone EH. Comparing apples and oranges. J Thorac Cardiovasc Surg. 2002;123:8-15.

14. Breiman L. Bagging predictors. Machine Learning. 1996;24:12340.

15. Diggle PJ, Heagerty PJ, Liang KY, Zeger SL. Analysis of Longitudinal Data. 2nd ed. New York: Oxford University Press; 2002. 


\section{Appendix E1. Variables Used in Multivariable Analysis \\ Demographics}

Age $(\mathrm{y})$, sex, height $(\mathrm{cm})$, weight $(\mathrm{kg})$, body surface area $\left(\mathrm{m}^{2}\right)$, body mass index $\left(\mathrm{kg} / \mathrm{m}^{-2}\right)$

\section{Preoperative status}

New York Heart Association functional class, Canadian angina class, emergency operation

\section{Left ventricular function}

Left ventricular dysfunction grade $(1=$ none, $2=$ mild, $3=$ moderate, $4=$ severe), previous myocardial infarction, left ventricular ejection fraction $(\%)$

\section{Other cardiac comorbidity}

Atrial fibrillation, coronary artery stenosis (left main trunk, left anterior descending coronary artery, circumflex coronary artery, right coronary artery; $>50 \%$, any), number of coronary systems with $>50 \%$ stenosis, family history of coronary artery disease, ventricular arrhythmia, complete heart block, history of endocarditis, heart failure, number of previous cardiac operations, valve regurgitation, and stenosis (mitral, aortic, pulmonary, tricuspid)

\section{Noncardiac comorbidity}

History of hypertension, treated diabetes (insulin-/non-insulintreated), smoking, peripheral vascular disease, chronic obstructive pulmonary disease, carotid disease, renal failure, blood urea nitrogen $\left(\mathrm{mg} / \mathrm{dL}^{-1}\right)$, creatinine $\left(\mathrm{mg} / \mathrm{dL}^{-1}\right)$, bilirubin $\left(\mathrm{mg} / \mathrm{dL}^{-1}\right)$, cholesterol (total, high-density lipoprotein, low-density lipoprotein, $\left.\mathrm{mg} / \mathrm{dL}^{-1}\right)$, triglycerides $\left(\mathrm{mg} / \mathrm{dL}^{-1}\right)$, hematocrit $(\%)$

\section{Previous operation}

Previous operation type (CABG, valve, other), aortic valve, mitral repair, mitral replacement, left internal thoracic artery used, carotid endarterectomy, ventricular aneurysm repair, atrial septal defect

\section{Details of procedure}

Operative approach (sternotomy vs thoracotomy), propensity for thoracotomy, concomitant $\mathrm{CABG}$, number of internal thoracic artery grafts, aortic valve repair/replacement, tricuspid valve repair/replacement, ventricular aneurysm

\section{Experience}

Date of operation 
TABLE E1. Factors associated with mitral valve replacement rather than repair

\begin{tabular}{lcc}
\hline Factor & Estimate \pm SE & $\boldsymbol{P}$ \\
\hline Operative approach & & \\
Right thoracotomy & $0.77 \pm 0.32$ & .017 \\
$\quad$ Propensity score & $0.33 \pm 0.69$ & .6 \\
Demography & $0.46 \pm 0.107$ & $<.0001$ \\
$\quad$ Female & $0.0161 \pm 0.0045$ & .0003 \\
Older & & \\
Previous cardiac operation & $2.6 \pm 0.189$ & $<.0001$ \\
$\quad$ Prior MV replacement & $1.63 \pm 0.132$ & $<.0001$ \\
Prior MV repair & $0.50 \pm 0.135$ & .0002 \\
Prior AV operation & $0.29 \pm 0.097$ & .004 \\
$\quad$ More previous operations & $-0.68 \pm 0.33$ & .04 \\
$\quad$ Prior ASD (less likely) & & \\
Cardiac comorbidity & $0.49 \pm 0.062$ & $<.0001$ \\
Severity of MV stenosis & $0.29 \pm 0.116$ & .01 \\
Preoperative AF & $-0.52 \pm 0.150$ & .0006 \\
LAD (less stenosis) & & \\
Reoperation & $-1.28 \pm 0.47$ & .006 \\
AV repair (less likely) & $0.39 \pm 0.166$ & .02 \\
ITA use (less likely) & $-0.041 \pm 0.0181$ & .02 \\
Earlier date of operation &
\end{tabular}

$\overline{S E}$, Standard error; $M V$, mitral valve; $A V$, aortic valve; $A S D$, atrial septal defect; $A F$, atrial fibrillation; $L A D$, left anterior descending; ITA, internal thoracic artery. 